\title{
Push and Pull Factors behind Female Labor-force Participation Decision, a Study of Kerala and West Bengal: two States of India
}

\author{
Sayantani Roy Choudhury \\ Indian Institute of Planning and Management, Kolkata, India \\ i.sayantani.rc@gmail.com
}

\begin{abstract}
This paper wants to show whether the decision of female labor force participation depends on economic factors or social factors. Female labor force participation is an outcome of both the factors. It can be possible that, economic and social factors play two different kinds of role. This paper tries to identify those push and pull factors and examine the significance of those factors in the decision regarding female labor force participation in two states of India, Kerala and West Bengal. Whether the factors are macroeconomic like SDP, literacy rate and urbanization, which can 'pull' FLPR up, or, the factors are micro economic, personal, poverty, and insecurity, which can 'push' the FLPR. By using binary logistic regression method, it is found in the paper that the micro level personal factors have more powerful influence on FLPR. The paper suggests that if we want to judge women's development through the FLPR, first we search for the factors behind that high FLPR. If the underline factors are 'push factors', the formula for GDI calculation should also be altered.
\end{abstract}

Keywords: Female labor force participation, Economic factors, Social factors, Development, Binary logistic regression, Gender related development index

\section{Introduction}

Economic prosperity affects the overall situation of female population of an area. It also influences the decision of female to participate in labor market. These changes can be viewed in a macro scale or in a micro scale. The two most popular indicators, GDI ${ }^{1}$ and GEM ${ }^{2}$, developed by UNDP in 1995 may help us to identify the macro-scale changes; but these may not be ideal for knowing the micro-scale changes. Female labor force participation decision may depend on various micro-level, personal as well as social factors. Some can be identified as 'pull factors' like high education, skill etc; some are 'push factors' like poverty, family burden, high dependency ratio. Policy makers should have a close look on each and every factor before setting some policies towards improvement of women. GDI and GEM should also be modified to judge the actual situation of women in an area.

\section{Literature Review}

The studies which examine the relationship between economic development \& female labor force participation have found quasi-linear or U-shaped association. Female participation in labor force is positive with some macroeconomic indicators, negative with some others. Ward (1984), Marshall (1984), and Semyonov and Shenhav (1988) have found that patterns of investment and economic dependency in the world capitalist system negatively affect the status of women. The results of the efforts to link economic dependency to women's status have not been uniform, but they have generally supported the hypothesis that women are less likely to gain access to the labor force in nations that are highly dependent on more developed nations for investment capital or trade (Marshall 1984, for a dissenting voice). Ward (1984) found that when women controlled for measures of dependency, the association was negative. Other cross-national comparisons, however, have described a positive or curvilinear association between economic development and women's share of the labor force (Pampel and Tanaka, 1986; Ramirez, 1981; Semyonov, 1980; Semyonov and Shenhav, 1988; Weiss, Ramirez, and Tracy, 1976). Explanations for a positive association have suggested that the shift from agricultural and heavy manufacturing to service and light industry provides jobs considered appropriate for women and that women's entry into a few areas traditionally reserved for men (say, higher education) tends to open up other occupational areas. The empirical disagreements may be resolved through a research design that addresses causal, rather than simply correlational associations 
between economic development and women's labor force status. Panda (2003) explores one of the key issues in current research on gender and development: the links between poverty and young women's employment. The analysis provides strong evidence for a U-shaped relationship between household economic status (and class status) and women's current employment status. The interplay of economic factors and cultural factors as determinants of women's employment is important both on the supply side of the labor market and women's ability to obtain employment. Several researchers hypothesized that female labor force participation rate exhibits a U-shape during the process of economic development. Tansel (2002) provides time series evidence on female labor force participation rates in Turkey and considers its cross-provincial determinants. Further, unemployment had a considerable discouraging effect on female labor force participation while the impact of education was strongly positive.

The hidden unemployment computations indicate that urban female unemployment rate is underestimated and the discouraged-worker effect for women is substantial. Harris, (2005) shows in her paper the two aspects of this gendered process, the first being 'productive deprivation'. Using field evidence from south Asia, the impact of technological change is shown to be strongly net labor displacing and strongly biased against female labor. At the same time, poverty ensures the persistence of petty commodity production, where women are either self-employed or 'unwaged' family workers. In case of female labor, decision used to take not only on the basis of economic variables, but also on social variables. There are different kinds of social variables which can influence female labor force participation decision. Nam (1991) investigates the determinants of labor force participation of women living in male-headed households in Seoul, South Korea, at two points in time, 1970 and 1980. Analysis of data from the 1970 and 1980 Korean Population Censuses suggests that both women's educational level and the family economic status determine women's labor force participation in Seoul. Women with middle school education or above are more economically active than those with no education. Women from lower economic backgrounds are almost two to three times more likely to be employed than those in high-status families. Saget (1999), Catherine closely examine the effect on a married woman's labor supply decision of non-labor income and of her own wage rate in a transition economy. Bun Song Lee, Soomyung Jang, include demographic characteristics as independent variables, such as marital status, education, age, migration status, whether she lives with person who is older than 60 . They also include city's labor market conditions, such as the unemployment rate; the percentage of workers employed in the service sector and in the manufacturing sector, Heather (2000) finds that culture plays a role in explaining inter-ethnic variation in the gender gap in labor force participation rates (LFPR). However, Antecol was unable to determine what the components of culture, such as differences in preferences regarding family structure and women's role in market versus home work, actually are and how to quantify these components in an empirically meaningful manner.

Sebastian and K Navaneetham, uses multivariate logistic regression analysis to determine the factors that influence female work participation. The study uses both individual characteristics - level of education, age, marital status, religion, place of residence - and household characteristics - economic status, husband's education and employment - to examine the likelihood of women being in the work force. The results show that education, age, marital status, place of residence, economic status and husband's employment turned out to be significant in determining women's entry into the work force. Within education, diploma and professional education shows maximum odds ratio where women with diploma and professional education have six and eighteen times more probability respectively to be employed compared to women with higher secondary or secondary education. It shows importance of skill-oriented education rather than general education in improving the employability of women. Lanot \& Muller (1997), the results show that the earnings function in the informal sector is strictly concave in hours, and positively related to the education and experience of workers and the capital of the family firm. The presence of young children have a negative impact on the labor supply whereas that of other female members makes easier the supply of labor which is consistent with the existence of substitutability in the domestic chores. Other children, age and marital status of the worker also influence the labor supply. Engelhardty \& Prskawetzz (2002), selected variables based on existing macro demographic theories. They apply aggregate descriptive representations of the time series and cross-country evolution of fertility, female employment and a set of labor market, educational and demographic variables and indicators of social policy. Hotchkiss (2005) determines that the weaker positive pull of education into the labor market and weaker labor market conditions are the observed factors that contributed the most to the decline in the labor force participation rate. Foley and York (2005) show, on the 
supply side, explanations for this common experience have pointed to increased education, and consequently real wages, for women, as well as growth in the demand for female labor. They focus on the role of children in explaining this trend. Several studies for developing countries have come up with econometric evidence to indicate that an inverse relationship exists between supply of labor and wage rate at low level of wage, especially for women in rural areas.

In the paper of Purnamita and Bishwanath (2005), this issue is investigated for rural female labor supply in India using NSS data for 1999-00. The results indicate that supply of female labor from below poverty line households in rural areas is inversely related to wage rate and the number of earning members in the family. According to Mitra (2006), the increased rate of growth of output in this period has not been translated into increased employment opportunities for urban women workers. The paper also analyses the sectoral shares of employed females, the annual average rate of growth of employment for urban women and the employment patterns. It shows an increase in the regular but subsidiary activities of urban women workers along with rising open unemployment rates and deteriorating work conditions in terms of lower wages and lack of non-wage remuneration. Therefore, most of the researchers searched for the relationship within different economic characteristics, personal components and level of female labor force participation. In the construction of GDI, three things are taken as per capita income, educational attainment and life expectancy. The construction of this index, particularly the income component, relies heavily on measurement of female labor force participation rate (FLPR). Now this FLPR may not be an appropriate Indicator due to absence of reliable data. But if we can rely on data, it may also be misleading. A correct data may not show the correct picture of that area. FLPR may come from some good factors like development, literacy, urbanization; it may also come from some negative factors like poverty, distress etc. That implies, a good amount of FLPR may reveal some positive things, or some negative things. Again, a low value of FLPR may not be due to underdevelopment, there may be other factors behind that. I focused on India to examine some of these factors. I have selected India because of its diversity among the states. Geographically, its states have huge variation and as we all know, geography, climate etc. can change work culture. Some of the Indian states are agricultural, some are industrial; some are very poor, some are rich. Some Indian states are rich with Hindu population, some with Muslim and some with SC, ST and OBC. Each and every state has different history, different belief and different culture. Their female labor force participation rates also have huge variations, from as low as about $15 \%$ to as high as about $44 \%$ (Census 2001). If we judge this fact by our census data, 2001; it would be clear. According to Census 2001, the FLPR is lowest for states like Kerala \& West Bengal.

Table 1: Female labor force participation rates

\begin{tabular}{ll}
\hline States & FLPR \\
\hline Andhra Pradesh & 35.11 \\
Assam & 20.71 \\
Bihar & 18.84 \\
Gujarat1 & 27.91 \\
Haryana & 27.22 \\
Himachal Pradesh & 43.67 \\
Jammu \& Kashmir & 22.45 \\
Karnataka & 31.98 \\
Kerala & 15.38 \\
Madhya Pradesh & 33.21 \\
Maharashtra & 30.81 \\
Orissa & 24.66 \\
Punjab & 19.05 \\
Rajasthan & 33.49 \\
Tamil Nadu & 31.54 \\
Tripura & 21.08 \\
Uttar Pradesh & 21.94 \\
West Bengal & 18.32 \\
\hline
\end{tabular}

Source: Census of India, 2001 
It is highest for the states Himachal Pradesh, Rajasthan, Madhya Pradesh. But if we think the low value of FLPR in Kerala \& West Bengal is associated with underdevelopment, low literacy, poverty, then we might be wrong. Because in these two states State Domestic Product (SDP), literacy rate, urbanization, is very good. Therefore a low FLPR, which lead to a low income component and hence to a low GDI may be misleading in this case. So there may be some other factors which are influencing FLPR. The objective of this paper is to find out the factors behind the low female labor force participation rate in Kerala and West Bengal. Whether the factors are macroeconomic like SDP, literacy rate and urbanization, or, the factors are micro economic, personal, whether 'push factors' are more powerful or 'pull factors'. Let's analyze this by looking at the two states, Kerala and West Bengal separately. Now, Kerala, West Bengal have a good SDP, good urbanization \& a good level of female literacy rate and with these a very poor level of economically active female population.

Table 2: Development indicators in some states

\begin{tabular}{lllll}
\hline STATE & FLPR & LITERACY & URBANIZATION & SDP \\
\hline West Bengal & 18.32 & 68.64 & 28.03 & 43301.4 \\
Kerala & 15.38 & 90.92 & 25.97 & 22762.7 \\
\hline
\end{tabular}

Source-Census of India, 2001

Theoretically, the effect of education on female labor force participation is ambiguous. We can differentiate between the effect of education on the decision to participate in the labor market and on the decision of how much time to spend in the labor market. Education has a positive effect on the decision to participate in the labor market for two reasons. First, if education is considered as an investment in human capital then the recipient has to work in order to recover cost of education. Second, if education is considered a consumption activity, the recipient will be induced to work because of higher earning potential since the opportunity cost of not working is higher. The effect of education on women's duration of work depends on the relative strength of two forces: the substitution effect and the income effect. First, education increases the potential earnings and therefore the cost of not working. This will increase the duration of work. Thus, it is a positive effect. Second, as a result of higher earnings, income target is achieved sooner. The part of higher income then could be allocated to consume more leisure and work less. And, it is a negative effect. The net effect of education depends on which force dominates. State domestic product is another development indicator which I have taken. Two other economic factors are associated with SDP as well as with FLPR. These two are wage rate and unemployment rate of that area. Economic theory posits that the effect of female wages on female labor force participation depends on the relative strengths of substitution and income effects. The substitution effect will be positive since higher female wages will mean more female labor force participation. The income effect will be negative since as income raises workers desire more leisure and less work. Assuming that the income effect is small, the overall effect of female wages on female labor force participation will be positive. On the other hand male wages are expected to have a negative influence on female labor force participation since the higher the wages of the husbands the less likely that the wives need to work Further, they were not reliable since they were averages for those workers who were covered by the Social Security Institution, which was a small portion of the population.

One can describe local labor market conditions with the provincial unemployment rate. The effect of the unemployment rate on female labor force participation is ambiguous depending on the relative strengths of "discouraged-worker effect" and the "added-worker effect". The provincial unemployment affects the probability that women entering the labor market will find a job. The higher the provincial unemployment rate, the less likely will it for a woman to find a job. Economic and psychological costs associated with job search will be higher when the local unemployment rate is high. For these reasons, women may be discouraged from looking for a job and drop out of the labor force. Therefore, the discouraged-worker hypothesis implies a negative effect of the local unemployment on female labor force participation. According to the added-worker hypothesis when men lose their jobs with a rise in local unemployment rate, wives might enter the labor force in order to compensate for the loss in the family income. The added-worker hypothesis implies a positive effect of the local unemployment on the female labor force participation. However due to paucity of jobs for women, the added-worker effect is expected to be small. Therefore, the discouraged-worker effect is likely to dominate the added-worker effect producing a negative effect of local unemployment on female labor force participation. The third macroeconomic factor in my model is 
urbanization. Urbanization also has two different effects on FLPR. Urbanization brings new industries; new job opportunities and this can increase FLPR. But these new jobs may need skill. The Indian women, mostly unskilled, may not get these opportunities. Again, in the states of India, where women are mainly engaged in agriculture, may lose work opportunity with high rate of urbanization. So we may not get a very pronounced positive or negative relationship with all these variables. But in case of Kerala and West Bengal the negative impacts of these three variables may be more powerful. The district level figures are showing the same facts. The districts of West Bengal, which are more urbanized, whose literacy rates are very high \& which have high District Domestic Product (DDP); have lower FLPR. Whereas the districts which are less urbanized, have low literacy rate, low DDP have higher FLPR. The same thing can be seen in case of Kerala.

\begin{tabular}{lllll}
\multicolumn{6}{l}{ Table : Districts of West Bengal } \\
\hline DISTRICTS & FLPR & per c DDP & literacy rate & urbanization \\
\hline Darjiling & 10.18 & 18529.18 & 62.94 & 32.44 \\
Jalpaiguri & 11.3 & 16749.07 & 52.21 & 17.74 \\
Koch Bihar & 10.73 & 13855.35 & 56.12 & 9.1 \\
Uttar Dinajpur & 11.47 & 11182.86 & 36.51 & 12.06 \\
Dakshin Dinajpur & 12.14 & 14579.19 & 54.28 & 13.09 \\
Maldah & 13.7 & 14777.2 & 41.25 & 7.32 \\
Murshidabad & 7.84 & 13392.39 & 47.63 & 12.49 \\
Birbhum & 9.47 & 12791.72 & 51.55 & 8.58 \\
Barddhama & 7.5 & 17537.98 & 60.95 & 37.18 \\
Nadia & 6.76 & 16211.46 & 59.58 & 21.27 \\
North 24 paragana & 5.29 & 14768.32 & 71.72 & 54.3 \\
Hugli & 7.71 & 16279.65 & 67.21 & 33.48 \\
Bankura & 15.59 & 15741.64 & 49.43 & 7.37 \\
Puruliya & 17.62 & 13044.67 & 36.50 & 10.07 \\
Medinipur & 11.14 & 15526.01 & 64.42 & 10.49 \\
Haora & 4.23 & 15591.44 & 70.11 & 50.39 \\
Kolkata & 5.54 & 33299.5 & 77.30 & 100 \\
South 24 paragana & 5.59 & 13630.22 & 59.01 & 15.77 \\
\hline
\end{tabular}

Source-Census of India, 2001

Table 4: Districts of Kerala

\begin{tabular}{lllll}
\hline DISTRICT & FLPR & urbanization & Net DDP & Literacy rate \\
\hline Kasaragod & 20.8 & 19.42 & 216355 & 79.8 \\
Kannur & 15.2 & 50.46 & 427050 & 89.57 \\
Wayanad & 22.8 & 3.76 & 138645 & 80.8 \\
Kozhikode & 8.1 & 38.25 & 506583 & 88.86 \\
Palakkad & 21.1 & 13.62 & 406713 & 79.31 \\
Thrissur & 15.1 & 28.21 & 561455 & 89.94 \\
Ernakulam & 17.1 & 47.65 & 692644 & 90.96 \\
Idukki & 28.1 & 5.07 & 225272 & 85.04 \\
Kottayam & 13.9 & 15.35 & 394828 & 94.45 \\
Alappuzha & 20.2 & 29.36 & 387813 & 91.14 \\
Pathanamthitta & 13.2 & 10.03 & 228304 & 93.71 \\
Kollam & 16.7 & 18.03 & 461379 & 88.6 \\
Thiruvananthapuram & 14.4 & 33.78 & 572431 & 86.26 \\
\hline
\end{tabular}

Source-Census of India, 2001 


\section{The district-level regression shows this fact clearly}

If we do regression with the model,

Female labor force participation rate $=[\mathbf{a} 1+\mathbf{a} 2 *$ DDP $+\mathbf{a} 3 *$ literacy rate $+\mathbf{a} 4 *$ urbanization $]$ : With district level data of West Bengal, we get the following result. R-square- 0.68

\begin{tabular}{lllll}
\hline variables & urbanization & Literacy rate & DDP & intercept \\
\hline Coefficients & -0.102 & -0.199 & 0.0004 & 15.87 \\
(t-values) & $(-1.95)$ & $(-2.7)$ & $(2.21)$ & $(3.49)$ \\
\hline
\end{tabular}

With district level data of Kerala, we get the following result: R-squre- 0.47

\begin{tabular}{lllll}
\hline variables & urbanization & Literacy rate & DDP & intercept \\
\hline Coefficients & -0.438 & -0.0005 & -0.084 & 59.15 \\
(t-values) & $(-1.635)$ & $(-0.438)$ & $(0.668)$ & $(2.685)$ \\
\hline
\end{tabular}

It shows a very clear relationship with the variables. R-square is high with significant t-statistics. The districts of West Bengal \& Kerala reveal a prominent negative relationship between female labor supply \& female literacy rate and rate of urbanization. It may be due to some economic factors or because of stronger push factors coming through some personal characteristics. Now the task is to find out the economic reason behind that low level of female working population. These two states have good SDP, good literacy rates, and good level of urbanization; and then why is female employment low? We may raise some points-

- The reason may be very high literacy rate

- The reason can be late start of industrialization

- It can be related with 'U-shape relationship'.

Relationship between women's education and work is not straightforward. The level of education is low in India; in 1991, only 39 percent of women and 64 percent of men were literate. The majority of those who are literate have only a primary education or less (RGCC, 1993). For men, as the level of education rises, the share of main workers generally increases. Just over one-third of literate men, who have no formal education, work as main workers. While three-quarter of those with post-high school educations are similarly employed. The effect of education on the employment status of women is not so straightforward. Higher levels of education for women do not directly translate into higher proportions of main workers. For example, 18 percent of illiterate women are employed as main workers, while just 11 percent of those with high school educations are employed as such. About half of all women who receive a post-secondary non-college diploma are employed as main workers. These women likely have received training for specific jobs. Surprisingly, women with university degrees do not have relatively high employment rates; only 28 percent of these women are employed as main workers. The confounding of the usual relationship between education and employment may be related to the likelihood that poorer and lower educated families require female members to work. Often, girls and young women work instead of receiving an education. Well-off and bettereducated families may send their daughters to school, but are able to afford to follow the cultural practice of keeping women at home after schooling is complete.

Table 5: State-wise Educated Unemployment Rate (per 1000) in India (UPS) in 1999-00

\begin{tabular}{lllllll}
\hline \multicolumn{1}{c}{ States } & Male & $\begin{array}{l}\text { Rural } \\
\text { Female }\end{array}$ & Total & Male & $\begin{array}{c}\text { Urban } \\
\text { Female }\end{array}$ & Total \\
\hline Andhra Pradesh & 72 & 150 & 84 & 61 & 145 & 72 \\
Assam & 185 & 583 & 234 & 121 & 316 & 156 \\
Bihar & 71 & 69 & 71 & 124 & 294 & 134 \\
Gujarat & 14 & 3 & 13 & 27 & 52 & 30 \\
Karnataka & 43 & 73 & 46 & 48 & 94 & 56 \\
Kerala & 150 & 491 & 253 & 99 & 419 & 212
\end{tabular}




\begin{tabular}{lllllll} 
Madhya Pradesh & 42 & 92 & 46 & 58 & 73 & 59 \\
Maharashtra & 70 & 72 & 70 & 68 & 117 & 75 \\
Orissa & 162 & 419 & 183 & 140 & 286 & 156 \\
Punjab & 48 & 215 & 60 & 47 & 64 & 49 \\
Rajasthan & 21 & 32 & 22 & 36 & 79 & 40 \\
Tamil Nadu & 106 & 149 & 113 & 51 & 148 & 70 \\
Uttar Pradesh & 37 & 71 & 39 & 71 & 172 & 79 \\
West Bengal & 110 & 379 & 130 & 98 & 292 & 121 \\
India & 68 & 204 & 82 & 66 & 163 & 79 \\
\hline Source: NSS Report No. 458: Employment and Unemployment Situation in India,1999-2000
\end{tabular}

The main feature of unemployment in Kerala is the very high incidence of unemployment among educated women. When educational level is factored, women found themselves at a great disadvantage in the early eighties irrespective of their level of education. The situation at the end of the 1990's changed somewhat wherein women with higher qualifications experienced lower unemployment compared to less educated men and women. In West Bengal also, we have same kind of situation. When education level is high, person becomes choosy about the nature of jobs, the location of jobs etc. generally, in India, female are engaged agricultural labor, as casual \& as household labor; well-educated women find low opportunity to be employed. Reason may be the late start of industrialization. Whereas from early 1980s almost all states of India show a positive trend in industrialization, Kerala \& West Bengal had a negative trend.

Table 6: GROWTH OF STRUCTURE OF SDP AT '93-'94 PRICES (\% SHARE IN SDP)

\begin{tabular}{lll}
\hline states & \% change from agriculture & \% change from industries \\
\hline KERALA & -23.43 & -2.39 \\
WEST BENGAL & -19.14 & -6.53 \\
TRIPURA & -38.53 & 172.73 \\
ANDRA PRADESH & -17.12 & 3.69 \\
ASSAM & -16.75 & 1.34 \\
BIHAR & -20.78 & 21.78 \\
GUJRAT & -22.77 & 6.19 \\
HARYANA & -26.30 & 7.92 \\
HIMACHAL PRADESH & -31.68 & 27.40 \\
J\&K & -2.43 & -22.48 \\
KARNATAKA & -26.90 & 5.73 \\
MADHYA PRADESH & -27.39 & 34.55 \\
MAHARASHTRA & -22.56 & -10.78 \\
MANIPUR & -22.54 & 28.88 \\
MEGHALAYA & -6.72 & 14.56 \\
ORISSA & -14.75 & 12.84 \\
PUNJAB & -14.75 & 11.36 \\
RAJASTHAN & -13.24 & -4.36 \\
TAMIL NADU & -31.95 & 16.22 \\
\hline
\end{tabular}

Source:- RBI: Handbook of Statistics on Indian Economy

The table 6 shows, between 1993-2001 the growth rate of agriculture as well as industrial sector was negative for Kerala and West Bengal.. For agriculture it was negative in all states; but for industry except a very few states the growth rate was positive. Since we are concerned about the unemployment data of 2001, some part of this must be due to this negative growth rate of industry. Next, we can analyze the U-shape relationship here. Hypothesis is, when an economy starts developing at a high speed, female labor force participation declines initially \& after some time it will start rising. From the table 7, it can be shown that the growth rate of net SDP was low in Kerala compared to other states during 1980s. But it moves upward very 
strongly in 1990s. In case of West Bengal the \% change of SDP was not very low, but the rate has increased much in 1990s.

Table 7: Growth of net SDP at factor cost at constant prices (Rs. Crores)

\begin{tabular}{lll}
\hline STATES & \%change & \%change \\
\hline & '85-'86 over'80-'81 & '99-'00over'95-'96 \\
KERALA & 6.88 & 20.57 \\
WEST BENGAL & 21.02 & 33.12 \\
TRIPURA & 9.85 & 42.24 \\
ANDRA PRADESH & 27.02 & 20.77 \\
ASSAM & 30.20 & 10.30 \\
BIHAR & 30.62 & 28.89 \\
GUJRAT & 25.46 & 18.66 \\
HARYANA & 37.90 & 27.17 \\
HIMACHAL PRADESH & 14.14 & 27.29 \\
J\&K & 17.14 & 21.39 \\
KARNATAKA & 20.51 & 38.28 \\
MADHYA PRADESH & 16.54 & 21.91 \\
MAHARASHTRA & 23.42 & 21.34 \\
MANIPUR & 28.00 & 41.36 \\
MEGHALAYA & 18.89 & 25.90 \\
ORISSA & 19.87 & 11.85 \\
PUNJAB & 33.15 & 21.89 \\
RAJASTHAN & 25.71 & 23.97 \\
TAMIL NADU & 30.11 & 27.70 \\
UTTAR PRADESH & 21.12 & 25.96 \\
\hline
\end{tabular}

Source: RBI: Handbook of Statistics on Indian Economy

Therefore, the poor rate of female labor force participation in Kerala and West Bengal may be due to the Ushape relationship. The low FLPR can also be due to the presence push factors present in women's personal or social characteristics. To find these other factors I take unit level data from NFHS-3 for the states Kerala, West Bengal. Here I frame the logistic model with some social factors which are very much related to FLPR.

\section{The binary logistic model}

Respondents' status $=\mathrm{f}($ sector, religion, number of household members, sex of household head, relation with household head, number of children below 5 years., number of elderly female members, educational attainment, current marital status, husband's occupation, structure of family, wealth of family).

Respondents' status: if 'working', then 1 and if 'not working', then 0: I have analyzed NFHS-3 unit level data. The '2005-06 National Family Health Survey (NFHS-3)' is the third in a series of national surveys; earlier NFHS surveys were carried out in 1992-93 (NFHS-1) and 1998-99 (NFHS-2). In NFHS-3, 18 research organizations conducted interviews with more than 2,30,000 women age 15-49 and men age 15-54 throughout India. Fieldwork for NFHS-3 was conducted from December 2005 to August 2006. NFHS-3, like NFHS-1 and NFHS-2, is a household survey which will provide estimates of indicators of population, health, and nutrition by background characteristics at the national and state levels. 
Table 8 : The results

\begin{tabular}{|c|c|c|c|c|c|c|c|c|c|c|c|c|c|}
\hline STATE & SECT & REL & CASTE & $\begin{array}{l}\text { HH } \\
\text { MEMB }\end{array}$ & CHILD & $\begin{array}{l}\text { ELDER } \\
\text { WOMEN }\end{array}$ & EDU & $\begin{array}{l}\text { REL } \\
\text { TO HH }\end{array}$ & $\begin{array}{ll}\text { SEX } & \text { OF } \\
\text { HH } & \end{array}$ & WEALTH & $\begin{array}{l}\text { MART } \\
\text { STATUS }\end{array}$ & $\begin{array}{l}\text { HUS } \\
\text { OCCU }\end{array}$ & STRUCTURE \\
\hline WB & $.62(-)^{*}$ & $.77(-)^{*}$ & 1.024 & $.96(-)^{*}$ & $.83(-)^{*}$ & 1.183* & $.894(-)^{*}$ & $1.03^{*}$ & $1.673^{*}$ & $.671(-)^{*}$ & $1.239^{*}$ & $.981(-)^{*}$ & $.840(-)^{*}$ \\
\hline $\begin{array}{l}\text { KERAL } \\
\text { A }\end{array}$ & $.67(-)^{*}$ & 1.003 & $.89(-)^{*}$ & $.941(-)^{*}$ & $.65(-)^{*}$ & $.932(-)$ & $1.091^{*}$ & 1.073 & $.724(-)^{*}$ & $.62(-)^{*}$ & $1.586^{*}$ & $.947(-)^{*}$ & $.863(-)^{*}$ \\
\hline
\end{tabular}

Source- calculated from unit level data

The regression result of the two states, West Bengal and Kerala are excellent. All the variables are having perfect connection with the dependent variable. And, most importantly, the variables like wealth of the family, husbands' occupation, being in rural sector have strong negative association with FLPR. In case of West Bengal, only 'caste' is having insignificant connections. All other independent variables have significance relationship with female labor force participation. Similarly, in case of Kerala, only two variables are insignificance, such as 'religion', 'relationship with family head'. That means, female labor force participation is closely related to micro economic, social factors in states like Kerala \& West Bengal. The reasons behind the odd pictures of these two states may be the importance of social characteristics. These social factors may overweigh the macro economic factors like state domestic product, level of female education, urbanization etc. Therefore, macro economic factors should be accompanied with social factors to create favorable conditions of having more female labor in the economy. In states like Kerala, West Bengal, high values of SDP, literacy rate may give women stability, security and it may play negative role on the decision of female labor force participation. If in some states, these macro economic factors fail to give women their necessary level of security or stability, women would take decision to go for work. What level of stability or security the women need that may also vary from one state to another. It may depend on the history, culture, nature of a particular state.

So we can say, there are two kinds of forces playing on female labor force participation decision. Some factors like SDP, urbanization, high literacy rate pulls female into labor force. Whereas, some factors are there which can push women out of the labor market. These factors are coming along with growth and development. If due to growth \& development, there is stability in the family, women may not join labor market. Due to higher level of literacy, women may become choosy about job \& if they don't get appropriate job, they may leave labor market. Again, urbanization, industrialization may bring demand for skilled labor which may push women out of the market. Therefore, it can be said that, in some states of India, pull factors, that is, SDP, urbanization, literacy rate are more powerful and in some states push factors like social and personal factors are more powerful. Each \& every positive economic factors are associated with those social factors which play negative role in influencing female labor force participation decision. The above discussion reveals the fact that we should not rely that much on the data of FLPR, even it is correct. To use the figure of FLPR into GDI calculation, we have to judge whether in that area, pull factors are more powerful or push factors. If it is push factor, the figure of FLPR may be showing wrong picture. The very high FLPR may be due to very significant negative push factors, i.e., women are joining labor force due to poverty, underdevelopment. These kinds of cases we find in some districts of West Bengal \& Kerala. If we calculate GDI with these very high FLPR, our calculations may show some wrong results. Therefore, if we find a high FLPR in an area, we have to judge about push \& pull factors. If it is due to push factors, we should reduce the weight of income component in GDI. Similarly, if we find a low FLPR in an area, and if it is due to positive pull factors, we should increase the weight of income component in GDI. In this way, we can make GDI a true indicator of women's situation.

\section{References}

Engelhardt, H. \& Prskawetz, A. (2002). On the Changing Correlation between Fertility and Female Employment over Space and Time, MPIDR working paper, 2002-052.

Foley, C. \& York Adam, G. (2005). The Effect of Children on Female Labor Supply in the United States from 1950 to 2000, Presented at the 2005 Western Economic Association International meetings.

Fred, C. \& Pampel, K. T. (2004/05). Economic Development and Female Labor Force Participation: 
A Reconsideration, University of Iowa, Discussion Paper No. 2004/05, The World Institute for Development Economics Research (WIDER)

Harris, B. W. (2005). Commercialization, Commodification and Gender Relations in Post-Harvest Systems for Rice in South Asia. Economic and Political Weekly, June 18, 2005.

Heather, A. (2000). The Role of Male Attitudes Towards Family and Sex Roles; Claremont Colleges Working Papers with number, 2003-03.

Hotchkiss, J. L. (2005). What's Up with the Decline in Female Labor Force Participation? Working Paper 200518.

Jane, A. W., Francisco, O. R. \& Terry, T. (1976). Female Participation in the Occupational System: A Comparative Institutional Analysis. Social Problems, 23(5), 593-608.

Mitra, S. (2006). Patterns of Female Employment in Urban India: Analysis of NSS Data (1983 to 1999-2000). Economic and Political Weekly, 41(48).

Muller, C. \& Lanot, G. (1997). Dualistic sector choice and female labor supply: evidence from formal and informal sectors in Cameroon; The Centre for the Study of African Economies Working Paper Series, 1997 Paper 57.

Nam, S. (1991). Determinants of Female Labor Force Participation: A Study of Seoul, South Korea, 1970-1980. Sociological Forum, 6(4), 641-659.

Panda, P. K. (2003). Poverty and Young Women's Employment: Linkages in Kerala; Economic and Political Weekly, September 20, 2003.

Purnamita, D. \& Bishwanath, G. (2005). Female Labor Supply in Rural India: An Econometric Analysis; Institute of Economic Growth, Delhi University Enclave, November 2005.

Ramirez, F. (1981). Statism, equality, and housewifery: A cross-national analysis. Pacific Sociological Review, 24(2), 175-95.

Saget, C. (1999). The determinants of female labor supply in Hungary. Economics of Transition, 7(3), 575-591.

Semyonov, M. (1980). The Social Context of Women's Labor Force Participation: A Comparative Analysis. The American Journal of Sociology, 86(3), 534-550.

Semyonov, M. \& Yeshouda, S. (1988). Investment Dependence, Economic Development, and Female Employment Opportunities in Less Developed Countries. Social Science Quarterly, 69, 961-978.

Susan, E. M. (1984). Politics and Female Status in North Africa: A Reconsideration of Development Theory. Economic Development and Cultural Change, 32(3), 499-524.

Tansel, A. (2002). Economic development and female labor force participation in turkey: time-series evidence and cross-province estimates, ERC Working Papers in Economics, 01/05.

Ward, K. B. (1984). Women in the World-System: Its Impact on Status and Fertility. Praeger, New York. 